\title{
O princípio de precaução ou os limites de um princípio político*
}

\section{Le principe de précaution ou les limites d'un principe politique ${ }^{* *}$}

\section{The precaution principle or limits of a political principle}

\author{
Simon CHARBONNEAU**
}

"Oprincípio de precaução se impõe em um mundo onde a ciência faz sonhar que tudo o que é possivel é desejável por ser realizável"

Jean Jacques Salomon'

Este texto toma a contramão da atitude que consiste em ver no princípio da precaução uma inovação jurídica capaz de responder sozinha às exigências de proteção face aos novos riscos (OGM, "vaca louca", etc.). Ao contrário, visa a colocar em evidência seus limites enquanto simples princípio do direito positivo. O texto, que defende que o alcance deste princípio não pode ser apreciado levando-se em conta apenas essa dimensão, o liga, ao contrário, a uma filosofia social e política que levanta a questão da própria legitimidade desta ou daquela inovação. Um ponto de vista que se situa em uma perspectiva de antropologia jurídica e que requer uma abordagem interdisciplinar da inovação. Este texto am- plia os debates em torno do princípio de precaução, difundidos pela NSS em seus números precedentes (NSS / v. 9, n. 1$)$.

A adoção do princípio de precaução no início dos anos 90 por numerosas convenções internacionais (citamos particularmente o princípio 15 da declaração do Rio de Janeiro, em junho de 1992), pelo tratado de Maastricht (velho artigo 130 R-2), em seguida pela Lei Barnier de 2 de fevereiro de 1995 (que o inseriu ao artigo L200-1 de nosso Código rural, hoje inscrito ao artigo L110-1 do novo Código de Meio ambiente), está na ori-

* Publicado na revista NSS. 2001, v. 9, n. 2, p. 44-50/ O2001. Editions scientifiques et medicales Elsevier SAS. Todos os direitos reservados. Tradução de Carolina Duarte Damasceno Ferreira

** Professor titular em Direito ambiental, professor da Universidade de Bordeaux-I, IUT da Universidade de Bordeaux-I, Departanento de Higiene-SegurançaMeio ambiente. Endereço universitário: 33405 Talence cedex, França. Charbonneau ânse iula u-bordeaux.fr.

I SALOMON, I. I. Sinvire à la science: une certaine idee de futur. Albin Michel, Paris: [s.11], 1999. p. 303 
gem de uma literatura abundante, procedente tanto dos juristas ${ }^{2}$ como de economistas ${ }^{3}$ e cientistas. ${ }^{+}$

É fato que a adoção desse princípio representa uma incontestável inovação institucional, coisa rara em matéria jurídica. Efetivamente, até então a prevenção dos riscos sanitários e ambientais gerados pelo desenvolvimento técnico-econômico sempre era supostamente garantida por decisões públicas fundadas em experiências técnico-científicas e por um diálogo permanente entre atores administrativos e industriais. O parecer técnico que legitimava as decisões mencionadas era então tido como fundado em certezas científicas, corroboradas pela ideologia do progresso, triunfante durante os Trinta Gloriosos. Se, por acaso, sucediam acidentes ou poluições inéditas como foi outrora a doença de Minamata no Japão ou, atualmente, a da vaca louca, o retorno da experiência servia unicamente para melhorar a prevenção e trazer provas científicas que faltavam no início da atividade industrial em questão. Como já foi escrito, ${ }^{5}$ tratavase então, em virtude do princípio ideológico do desenvolvimento, de prosseguir a todo custo a atividade industrial ou autorizar as inovações tecnológicas, mesmo se acompanhadas por dispositivos, baseados em conhecimentos adquiridos, que deveriam garantir a segurança. Deve-se ressaltar que esse pano de fundo ideológico, que guia tradicionalmente tanto os especialistas como os políticos, é curiosamente oculto por um grupo de autores precipitados, da mesma forma que são omitidos os aspectos de sociologia política ligados à tomada das decisões nesse domínio, em particular o papel dos lobbys industriais.

O procedimento da precaução resulta, incontestavelmente, do questionamento das grandes certezas científicas, após o advento da crítica ecologista, nascida na Europa no início dos anos 70. É verdade que a crise ambiental, a partir de acontecimentos como a descoberta dos danos à camada de ozônio estratosférica, havia, nesse ínterim, emergido nas consciências, corroboran- do esse questionamento. A fé cega no progresso técnico-científico estava abalada pela primeira vez. Tratavase, dali em diante, de não mais esperar, como no passado, provas científicas decorrentes do retorno da experiência, mas antecipar, sem provas científicas tangíveis, acontecimentos graves e irreversíveis, tanto para a saúde pública como para o meio natural, tomando todas as medidas de precaução necessárias, que podiam levar até a abstenção da atividade de risco. Quanto a esse último enfoque, é preciso deixar claro que a atitude de precaução pode variar se envolver uma inovação perigosa que deve ser autorizada ou uma situação de risco já existente. Na primeira hipótese, essa atitude poderá levar até uma interdição provisória (à espera de resultados científicos mais positivos) ou definitiva, que implica na abstenção por parte do peticionário, enquanto no segundo caso serão tomadas medidas de salvaguarda, que se situam do lado oposto da abstenção administrativa.

Desde então, o emprego da precaução só pode se basear, como todas as definições mostram (ver a definição dada por nosso artigo L200-1 do Código Rural), em dois critérios. A gravidade e a irreversibilidade das conseqüências, de um lado, que fazem com que apenas os riscos coletivos maiores sejam envolvidos e, de outro, a incerteza científica, fonte de imprevisibilidade. O primeiro critério pressupõe, obviamente, a aquisição de um mínimo de certezas científicas, que não se reduzam a meras suspeitas, no tocante à avaliação preliminar do perigo existente ou por vir. O segundo supõe que existem controvérsias entre os especialistas, e que os conhecimentos sobre a matéria podem ser considerados amplamente insuficientes. No caso dos OGM e da vaca louca, e de um modo geral em todos os outros riscos em que os efeitos potenciais só podem se manifestar com o tempo, é evidente que esses dois critérios estão unidos.

As interpretações desse princípio variam segundo a prioridade de ordem ideológica que os autores atribuem ao desenvolvimento técnico, científico e econômico

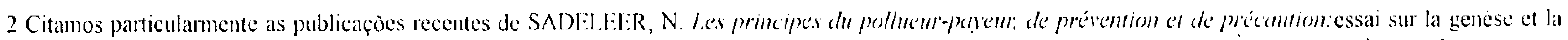
portée juridique de quelques principes en droit de l'environnement. [S.I.]: Ed. Bruylant, 1999, com prefácio de l:Ost; de ROUYERE, A. L'exigence de précaution

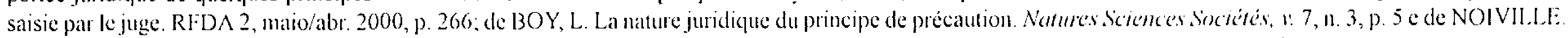
C. Principe de précaution et gestion des risques en droit de l'enviromement et de la santé, gue será publicado em lés perntes affiches.

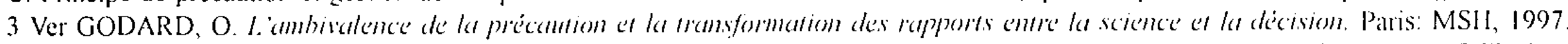

4 Ver as conclusòes, p. 211 e seguinte, de KOURILSKY, P.; VINEY, G.: Le principe de precaution: rappont au prenier ministre Odile Jacob. La Documentation Française, 2000.

5 Principe de développenent contre principe de précaution. Nantes Siciencés Sisciétés. 1: 6, n. 3. 1998, p. 45.
} 
em relação às preocupações sanitárias e ambientais. Ao sabor de suas tomadas de posição sobre essa questão, os autores oscilam entre uma interpretação insuficiente, mais próxima da prevenção clássica, que é a posição dos economistas e dos cientistas (ver as posições precipitadas de Godard e de P. Kourilsky), e uma interpretação bem mais exigente, que pode levar, às vezes, ao direito de moratória (ver meu artigo na NSS 1998), empreendida pelos juristas (ver particularmente M. A Hermitte ; C. Noiville, 2000; F. Ewald, 1998; P. Lascoumes, 1994; N. de Sadeleer, 1999; M. Remond-Gouilloud, 1992; L. Boy, 1999 etc.). Ao lado desses últimos, com exceção de alguns, de que M. A Hermitte, C. Noiville e P. Lascoumes, F. Ost (1995) e N. Rouland fazem parte, pode-se notar um incontestável déficit de reflexão política e sociológica, que não tem lugar definido na grande tradição positivista do nosso ensino jurídico. Segundo esse último posicionamento, a regra do Direito deve ser estudada sem levar em conta nenhuma referência aos valores e aos determinismos sociológicos que a fundam: uma tradição particularmente mutiladora da reflexão jurídica." Se o Direito dito positivo e técnico, do modo como ele ainda é ensinado nas nossas faculdades de Advocacia, é perfeitamente legítimo na ótica de formação dos que exercem as suas práticas (advogados, juizes e funcionários), ele o é muito menos no quadro de um ensino autenticamente universitário. Ora, a questão da precaução só adquire verdadeiramente sentido se analisada a partir de uma reflexão transdiciplinar sobre o fenômeno da tecnociência e da economia planetária nas sociedades ditas mais avançadas. Pretender dar conta de um tal princípio fora de qualquer contextualização política, cultural e econômica, que funda a problemática, é um disparate.

Se for adotada a visão da antropologia jurídica, o olhar que se pode lançar sobre o princípio de precaução muda completamente. Seja por sua natureza, sua finalidade ou função, esse princípio, hoje objeto de todas as retóricas, parece ser mais modesto do que o papel que Ihe querem atribuir. Aliás, ele só tem sentido sob a ótica de uma problemática político-jurídica muito mais vasta, a da aceitabilidade social, ao mesmo tempo dos riscos maiores e das medidas de precaução, pois, como obser- va Salomon, em La précaution est une attitude morale plutôt que scientifique (p. 307), esses limites são de várias ordens.

\section{Um déficit de ordem conceitual}

Fiéis à tradição positivista, os autores não abordam jamais a questão fundamental da pertinência da formulação conceitual de um princípio jurídico sob o ângulo da problemática que o funda. Nessa tradição kelseniana, estaria fora de cogitação abordar a questão do senso moral, político e sociológico da regra do Direito, porque se tratam de questões extrajurídicas.

No que tange o princípio de precaução, todas as definições dadas por textos internacionais e nacionais (SADELEER, 1999, p.138-166) retomam aproximadamente as mesmas expressões, interpretando-as de modo mais ou menos favorável à proteção do meio ambiente e da saúde; os critérios acima mencionados são sempre referidos, apesar de uma grande variedade de termos utilizados. No entanto, contrariamente do que afirma meu colega SADELEER $(1999$, p.167), podemos questionar se a conduta de precaução responde satisfatoriamente à dimensão real da problemática do risco ecológico.

Com efeito, esse procedimento, que não é novo, se volta principalmente, como observa NOIVILLE (p. 12 e seguinte), para a questão da avaliação dos riscos que preside atualmente todas as tomadas de decisão relativas à inserção no mercado de produtos nocivos ou à interrupção de uma atividade perigosa. Trata-se sempre de saber se a autoridade pública deve intervir tomando medidas de salvaguarda e se o industrial deve se abster de expor o consumidor a riscos. Tudo se direciona, como se escreve há alguns anos, a uma visão puramente gestatória dos riscos causados pelo desenvolvimento. Falta, de fato, uma dimensão essencial da problemática ambiental: a questão da aceitabilidade sociopolítica dos riscos coletivos maiores, que infelizmente ainda não encontrou nenhuma conceituação jurídica, que parece estar, atualmente, em condições de despontar. O princípio da precaução constitui, efetivamente, apenas um

6 Ver as análises roborativas de Norbert Rouland sobre as "Virgens estéreis" das nossas faculdades de Direito em sua notavel obra de antropologia juridica, citada muito raramente:. JACOB, O. Am c'mfins dir droit. 1991, p.180.

7 Ver meu antigo "De l'inexistence des principes jutidiques en droit de l'emiromenent". Dalloz legislativo, 12 de outubro de 1995, n. 17, p. 146. Esse enfoque é perfeitamente perceptivel na Comissão européa do dia 2 de fevereiro de 2000 ., consagrada a esse principio (suplemento a limrope linviromememt, número 561 ). 
parâmetro dessa problemática essencial: ele continua limitado à questão da importância do risco. É por essa razão que ele deve ser completado pelo princípio da participação do cidadão-consumidor na decisão, que não saberia se reduzir, como afirma Nicolas De Sandeleer ( 1999 , p. 337 e seguinte), a sua dimensão procedimental, ${ }^{\circ}$ sendo especialmente enriquecida pela questão fundamental da legitimidade da atividade que induz à tomada de um risco coletivo. A questão do benefício que certas inovações agroindustriais, como os OGM, trariam para o consumidor, que a adoção de novos meios de transportes rápidos ou perigosos trariam para o usuário ou, ainda, que os remédios criados pelo talento genético trariam para o doente, suscitam um balanço que a sociedade deve estabelecer para pesar as vantagens e os inconvenientes representados por essas tecnologias Não se trata, de forma alguma, de uma questão ligada à ciência, mas antes de um raciocínio vinculado à moral e à política. É por essa razão que, como Christiane Noiville, aqui acredita-se na necessidade da criação de novos conceitos jurídicos que abarquem essa problemática.

A essa fragilidade conceitual, que se deve ao fato desse princípio ter sido concebido por e para aqueles que decidem, é preciso acrescentar uma outra: a novidade completamente relativa da conduta de precaução. Todos os autores, de fato, concordam sobre um ponto (ver particularmente SADELEER, 1999, p. 173 e seguinte, e o artigo de ROUYÉRE, 2000, p. 272): o princípio de precaução se distingue do princípio de prevenção por se aplicar em situações de incertezas científicas. Se no procedimento preventivo clássico a decisão é supostamente tomada com o respaldo de pareceres fundados sobre certezas científicas, na precaução ocorreria o contrário. Esse leitmotiv da literatura jurídica na matéria nos pareceu perfeitamente contestável, pois a função desses dois princípios é idêntica, e isso por duas razões complementares.

Em primeiro lugar, é preciso frisar que uma prevenção autêntica, para ser eficaz, deve integrar a precaução. Todas as regulamentações ambientais clássicas, em vigor há aproximadamente 20 anos na Europa, integraram, de fato, a precaução através de procedimentos de estudos sobre o impacto ou sobre perigo, que podem sempre levar ao veto de uma autorização de um produto ou de uma atividade nociva, apesar da prática administrativa contrária na matéria. No caso das situações de risco existentes, a autoridade administrativa sempre teve igualmente a possibilidade jurídica de tomar medidas de precaução através de interdições apropriadas ou, por exemplo, retirando do mercado um produto nocivo (art. L.221 e seguinte do Código do Consumidor). Podemos citar também o notável principio Alara $(.1 s$ Low is Reasonnably achievable), que existe há muito tempo em matéria de radioproteção e almeja que as doses de irradiação recebidas sejam as mais fracas possíveis, tendo em vista a incerteza cientifica que envolve a questão do efeito sanitário de pequenas doses. A prevenção clássica, na verdade, integrou há muito tempo a incerteza científica, geralmente revelada pelo retorno da experiência, graças a procedimentos administrativos adequados que prevêem, por exemplo, a reatualização dos estudos preliminares de risco e as autorizações prévias que deles resultam.

Aliás, se as regulamentações clássicas tivessem verdadeiramente desempenhado o papel de prevenção, a degradação do contexto ecológico europeu teria sido, sem dúvida, menos grave do que ela é atualmente. Pretender, em vista da situação atual, que certezas presidiram a elaboração dessas regulamentações, considerando o retorno atual da experiência, é claramente um contra-senso! A poluição crescente da água por pesticidas e nitratos, do ar pelo ozônio troposférico e pelos óxidos de azoto, do solo por metais pesados, demonstra a fragilidade das supostas medidas de precaução. O sistema de prevenção dos danos ecológicos, fundado em prévias autorizações administrativas, legitimadas por pareceres mais ou menos sérios, se mostrou um fracasso, já que a própria precaução foi completamente ignorada em nome do princípio ideológico de desenvolvimento industrial. As notáveis certezas científicas, reflexos de uma época marcada por uma fé cega, logo irracional ( $\mathrm{J} . \mathrm{J}$ Salomon fala com bastante acerto da "mística do racional", p. 297 da obra citada), no progresso científico e técnico, se averiguaram completamente relativas!

Sob muitos aspectos, a prevenção, para ser confiável, deve recorrer à conduta da precaução que induz, às vezes, à abstenção pura e simples, e não apenas à imposição de limitações às atividades nocivas. No con-

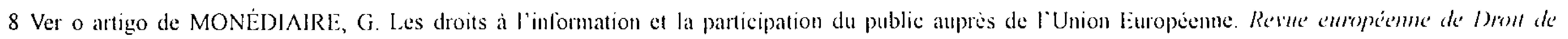
lemviremement, 11. 2-3, 1999. 
ceito restritivo de prevenção que dominava até o presente no plano das disposições regulamentares - principalmente na prática administrativa - essa conduta permaneceu excepcional, como mostram os regimes comunitários (diretiva 85/337) e nacionais (decreto modificado no dia 12 de outubro de 1977) de estudo de impacto prévio que, significativamente, sempre ignoram a opção zero em matéria de ajustes ou de projetos industriais.

Reciprocamente, a precaução se situa evidentemente no âmbito de uma abordagem preventiva clássica, já que ela recorre obrigatoriamente aos instrumentos regulamentares habitualmente utilizados em matéria de gestão de riscos. Se for tomado, por exemplo, o caso da disseminação das plantas transgênicas, citado por HERMITTE e NOIVILLE (RJE 3, 1993, p. 91), como uma amostra da aplicação do princípio de precaução, percebe-se que todos os instrumentos jurídicos da gestão de riscos, previstos pela diretiva européia 90/220, vinculam-se a uma concepção clássica da prevenção (estudo de impacto e autorização prévia de controle etc). Isso é provado pela necessidade atual de substituir essa diretiva por um texto mais rigoroso, em nome justamente de uma conduta de precaução, um texto de compromisso muito criticado pelos ambientalistas. Se for tomado igualmente o caso do precipitado relatório governamental de $P$. Kourilsky, a interpretação insuficiente que é feita da precaução, considerando-a como uma simples regra de vigilância destinada a reforçar e assegurar uma segurança melhor (ver p. 212), confirma-se completamente essa impressão. As recomendações feitas nesse último relatório se empenham, aliás, em ocultar o conteúdo politico desse princípio, a fim de garantir à técnico-burocracia sua capacidade tradicional de decisão e não prejudicar a inovação tecnológica, que é a veia da guerra econômica mundial

A prevenção é então indissociável da precaução, e querer distinguir a todo custo essas duas noções é um disparate, pois a segunda não passa, definitivamente, de uma interpretação mais exigente da primeira. O que resta, no entanto, é que esse princípio interpretado de um modo exigente, ao contrário do caso do relatório Kourilsky, hoje revoluciona a prevenção.

\section{Limites de ordem jurídica}

No tocante ao valor jurídico do princípio de precaução, as interpretações variam, porém não se opõem radicalmente, sendo que a maioria dos autores concorda em reconhecer a fraqueza desse valor. Para uns (ver DE SADELEER, 1999, p. 275 e seguinte, e também LAURENCE BOY, art. anteriormente citado, p. 7 e seguinte), um tal princípio possui uma incontestável potencialidade jurídica, devido particularmente à jurisprudência, enquanto, para outros, essa potencialidade permanece muito incerta.

No entanto, todos os autores admitem que, assim como os outros princípios do Direito ambiental, o princípio de precaução só pode consistir em instrumentos jurídicos de orientação (SADELEER, 1999, p. 279), destinados a guiar as decisões tomadas em matéria de segurança sanitária e proteção ambiental pelo legislador, a administração e a justiça. Em decorrência de sua generalidade, sobretudo quando estes instrumentos jurídicos não são definidos, como no artigo L174-2 do Tratado da União Européia (somente a comunicação precipitada da Comissão datada de 2 de fevereiro de 2000 os define com precisão), esses princípios se apresentam, do ponto de vista jurídico, como razoavelmente "viscoso", graças a sua profunda natureza política.

Em razão de sua maleabilidade, os instrumentos jurídicos podem de fato ser interpretados de forma variável, para não dizer contrária, pelas autoridades em questão. O "direito brando", hoje paradoxalmente tão celebrado pelos positivistas de outrora, renunciando à função rígida da regra de direito, deixa o campo social aberto às relações de poder e à ideologia dominante contemporânea, que é a do desenvolvimento. Se for tomado, por exemplo, o caso do dossiê europeu dos OGM, perceber-se-á que alguns Estados membros, como a Áustria ou a França, tendem a interpretar estritamente o princípio de precaução, já que as autorizações de disseminação de certas plantas transgênicas, como o colza, são recusadas, embora tivessem recebido carta branca da Comissão Européia, muito sensível ao lobby industrial e animada pela ideologia do desenvolvimento, que estima que a regulamentação instaurada pela diretriz $90 / 220$ fornece suficiente garantia ambiental. Essa divergência de interpretação entre as instâncias nacionais e européias deve ser acentuada em breve pela corte de justiça, tendo em vista a moratória de fato existente na matéria. Ela será ressaltada a partir de um arbítrio, de natureza mais política que jurídica, entre as preocupações ligadas ao desenvolvimento econômico e as que se vinculam à proteção do meio ambiente e da saúde pública. 
Da natureza jurídica ambivalente desse princípio resulta sua baixa "invocabilidade" pelo cidadão diante do juiz, que tenderá, como observa a colega Rouyère (2000, p. 278), a se contentar com um controle limitado. Na última jurisprudência do Conselho de Estado francês sobre a matéria (CE de 25 de setembro de 1998, Associação Greenpeace, França) - fiel a uma velha tradição de controle mínimo nos domínios teoricamente dependentes do julgamento científico - essa tendência transparece. Intimidado pela amplidão dos embates políticos e econômicos decorrentes de sua decisão, o juiz tenderá a se retrair em uma ótica jurídica estreita, que sempre coube a ele na França, para não ter que deliberar sobre questões de oportunidade ou sobre aquelas que dependem de um procedimento técnico. Conseqüência prática, as decisões tomadas tendem, em grande parte, a ser desfavoráveis ao meio ambiente, como mostra a jurisprudência atual da corte de Luxembourg, que sempre se inclinou a fazer primar, salvo talvez na matéria dos detritos (CICl: 7 de fevereiro de 1985, Associação da proibição aos maçaricos (brîleurs) usados, aff. 240/83), os princípios do liberalismo econômico que fundaram a Comunidade Européia e que são lembrados regularmente ao longo do Tratado da União e, em particular, no capítulo relativo ao meio ambiente (art. 174 , alínea 3, último parágrafo).

Em decorrência disso, os contra-poderes associativos terão muita dificuldade em se apoiar nesse princípio para fazer recuar as decisões administrativas, sempre politicamente favoráveis ao desenvolvimento econômico. De um modo geral, os princípios atuais do Direito ambiental foram concebidos como instrumentos a serviço daqueles que detêm o poder de decisão, contrariamente aos princípios gerais do direito e, sobretudo, aos direitos fundamentais, que também se destinam a ser utilizados pelo simples cidadão.

No entanto, subsiste que, tendo em vista a evolução de uma opinião pública muito mais sensibilizada às questões ambientais que no passado, um recurso mais freqüente ao princípio de precaução por parte da administração, assim como da justiça, poderia se registrar nos próximos anos, independentemente do valor de tal princípio. Essa evolução contribuirá então, obviamente, a dar-lhe um valor jurídico incontestável, que só fará confirmar a idéia antipositivista segundo a qual é o con- texto sociológico que determina os avanços jurisprudenciais, e não a validade jurídica teórica de um princípio.

Seja o que for, é evidente que, como observa Sadeleer (1999, p. 330 e seguinte), esse princípio não saberia substituir a existência de autênticos direitos fundamentais, com valor constitucional, que por natureza se destinam a serem invocados pelos fracos ou pelas minorias que aspiram a mais justiça. Sem cair na ilusão positivista, é indispensável reafirmar solenemente a função rigorosa, mas civilizada, da regra de direito, fundada em valores oriundos de nossa herança espiritual (ROULAND, p. 197).

Nesse sentido, é preciso dizer que a imaginação dos constitucionalistas permaneceu modesta, já que as constituições modernas reconhecem somente, através de definições variáveis, um direito geral, ao mesmo tempo subjetivo e objetivo, à proteção do meio ambiente, ao invés daquele que tem por objeto o controle dos riscos coletivos causados pelo desenvolvimento técnico-econômico. Esse direito ao meio ambiente foi concebido à imagem do direito ao trabalho ou à saúde, que pecam por sua generalidade ou truismo. Por mais útil que seja o reconhecimento desse direito, que implica em pesadas obrigações tanto para os poderes públicos como para os atores econômicos, é evidente que ele peca por um déficit conceitual no que diz respeito às causas estruturais que estão na origem da crise ambiental. É por essa razão que foi proposto, há muito tempo, após uma reflexão doutrinal," que novos direitos mais operacionais fossem institucionalizados, como o direito de moratória, sobre os riscos maiores inaceitáveis socialmente e o direito a um parecer contraditório e independente, ambos implicando, por sua natureza, em uma exigência de precaução. Na perspectiva de um certo domínio humano de um desenvolvimento que se tornou insustentável, poderiam ser igualmente definidos um direito às origens. destinado a regular a mobilidade planetária das mercadorias e dos homens, e um princípio do uso sustentável dos recursos naturais renováveis, que visasse a instaurar um equilíbrio entre as atividades humanas e a biodiversidade. Esse último princípio, aliás, foi reconhecido recentemente pelo novo artigo $L$ 420-1 do Código Ambiental proveniente da lei de caça de 26 de julho de 2000 (J0 do 27). Chamado a se estender sobre outras

9 Ver nosso artigo publicado na revista Liprit. em dezembro de 1981, cujas leses desenvolvemos no úlbimo capitulo do nosso livro precipitado, la géshon de l'impossible. Economica, 1992. 
numerosas atividades, esse último princípio deveria conferir, no futuro, mais direitos aos particulares que o de precaução, graças a sua própria concepção.

\section{Conflitos de direitos de ordem estrutural}

Como sublinha François Ost em um capítulo sobre a deep ecology:" o direito é produzido pelos homens e para os homens. Hans Jonas, por sua vez, tinha feito a mesma observação a propósito da moral cristã, em seu livro le principe de responsabilite (Ed. du Cerf, 1990). Os princípios do direito ambiental só podem ser relativos ao vínculo entre o homem e a natureza. Ora, esse vínculo sempre foi problemático, pois implica em tuma tensão permanente entre uma situação em que, num primeiro momento, o homem se submetia à natureza, e em outro, atual, o mesmo homem a destrói e artificializa em razão da potência de seus meios. Como ressaltou com bastante precisão Ost (1995, p. 47), os direitos tradicionais do homem, em particular o da propriedade, sempre refletiram seu desejo de dominação da natureza, enquanto o direito ambiental visa a, ao contrário, controlar os impactos das atividades humanas sobre essa última. Entre as duas categorias de direitos, já existem relações conflituosas, que poderão futuramente ganhar uma nova dimensão com a globalização e uma radicalização das políticas ambientais sanitárias. Uma "ecocracia" planetária, fundada sobre a aliança da ciência e da ideologia naturistas, poderia mesmo, un dia, prejudicar essa tensão criadora que deve existir entre a natureza e a liberdade humana." Os usos mais tradicionais, como a pesca e a caça recreativa, poderiam, por exemplo, ser questionados em nome de uma visão sacralizada da "mãe natureza". Em nome do princípio de precaução, medidas exorbitantes de higiene e segurança, visando a proteger os homens de qualquer tipo de risco, poderiam igualmente ser tomadas, em detrimento das liberdades públicas elementares e da proteção à vida privada. Discriminações sociais que prejudicassem o princípio de igualdade diante dos impostos públicos poderiam resultar também da generalização de "ecotaxas" e de normas ambientais cada vez mais rigorosas.
Como constata com bastante acerto o colega Nicolas De Sadeleer, o principio de precaução entra desde o presente em conflito com direitos fundamentais tradicionais, como os da propriedade, da liberdade de indústria e comércio, da livre circulação de mercadorias e da igualdade (SADI:LIEIER, 1999, p. 357 e seguinte). O princípio jurisprudencial de proporcionalidade pode, efetivamente, servir para manter um equilíbrio entre o respeito desses direitos e a nova obrigação da precaução (SADI:LLII:R, 1999, p. 384 e seguinte).

Não obstante, a avaliação da proporção optimal continua dependendo da competência discricionária do juiz, que deve se aplicar em definir o interesse geral em cada caso que the é submetido: um exercício sempre arriscado. $\dot{E}$ por isso que a determinação do optimum favorável ao interesse geral pode se apoiar na problemática reversível da aceitabilidade social dos riscos maiores. Pois, em nome dos valores de liberdade e igualdade que fundam nossos direitos fundamentais, a questão da aceitabilidade sociopolítica das medidas de prevenção se coloca de forma legítima. Trata-se aqui de se referir não apenas aos custos econômicos mencionados na definição do princípio de precaução, citado no artigo L.110-1 do novo Código Ambiental, mas também aos de ordem social e, finalmente, às conseqüiencias culturais e éticas que nunca são mencionadas, embora desempenhem um papel fundamental. Essa problemática vai, com efeito, bem além do raciocinio economista custo-benefício, que está na origem da notável jurisprudência da avaliação comparativa, de que se conhece bem o balanço pouco glorioso. ${ }^{2}$ lsso se torna ainda mais verdadeiro se for considerado que a noção de custos economicamente aceitáveis é perfeitamente ambivalente, já que ela sugere, de um lado, uma limitação da precaução, que pode ser inaceitável socialmente, mas, de outro, pode significar também que a tomada de riscos é economicamente muito custosa e é preciso, em consequiência, se abster (o caso do reator nuclear - surgenerateu - de Creys Malville, desativado por decisão governamental, pode servir de exemplo). Definitivamente, o raciocínio jurídico está aqui condicionado por um arbitrio de natureza política, que não somente faz referência às vantagens e inconvenientes de um risco coletivo, mas também se apóia sobre valores e crenças. 
Resta saber como pode ser instaurado esse arbítrio no plano institucional, já que o que é julgado aceitável pelos que decidem no âmbito público, pode não o ser para o juiz ou para certos grupos de pressão. O apelo ao debate entre contrários, ao diálogo, ao consenso que é repetido exaustivamente nesse domínio, não resolve de modo algum a questão principal, e Christine Noiville tem razão em falar dos efeitos perversos da aceitabilidade ( $p$. 17). No que tange o desenvolvimento industrial, riscos sanitários outrora considerados socialmente aceitáveis (ex: o amianto) podem não o ser mais. Observa-se atualmente as derivas higienistas dos consumidores em matéria alimentar, enquanto o risco dos automóveis, muito mais verificado pela experiência, está sendo omitido coletivamente. O recurso à lógica demográfica, habitualmente invocada, não impedirá cegueiras coletivas particularmente perigosas no plano sanitário ou ambiental (a guerra sendo a ilustração extrema disso!), nem ataques exorbitantes às liberdades fundamentais, em nome da saúde pública e da natureza sacralizada.

Desse ponto de vista, o exemplo das derivas securitárias de certas regulamentações européias é absolutamente esclarecedor. As normas de higiene, de segurança e meio ambiente, definem os limiares de inocuidade, que supostamente deveriam se basear nos conhecimentos científicos disponíveis na matéria. O procedimento depende, ao mesmo tempo, da prevencão e da precaução. Esses limiares, que às vezes são contestados em ecotoxicologia, pois se pautam no postulado da poluição residual incompreensível, ${ }^{13}$ são sempre concebidos para atividades de natureza industrial; eles são então completamente inaptos às atividades de natureza familiar ou artesanal, que apresentam riscos sanitários e ambientais absolutamente menores. Se for tomado, por exemplo, o caso da diretiva comunitária 92/46, do dia 16 de junho de 1992, que fixa as regras sanitárias para a produção e a inserção no mercado do leite fresco, perceber-se-á que a Comunidade Européia impõe à produção familiar as normas de higiene concebidas para as leiterias industriais. Esse texto instaura uma regulamentação técnica hipercomplexa, totalmente inassimilável para os produtores que fabricam seus queijos nas montanhas, seguindo métodos ancestrais. Podemos citar igualmente o caso dessa diretiva 93/43, aplicável na Europa desde maio de 2000, que impõe regras de higiene draconianas aos mercados rurais e, consequientemente, investimentos desproporcionais ao risco. Essa última regulamentação, muito contestada na França nos meios agrícolas, e que está sendo revisada atualmente, se coloca como efetivamente inaceitável economicamente e socialmente, tendo em vista, por um lado, os investimentos exorbitantes na segurança impostos aos pequenos produtores e, por outro, a baixa gravidade das conseqüiencias sanitárias, minimizadas pela proximidade dos lugares de produção e certamente não avaliadas por estudos epidemológicos. O recurso abusivo ao princípio de precaução pode mesmo, paradoxalmente, induzir, a longo prazo, a riscos sanitários e ambientais inaceitáveis. Isso é particularmente verdadeiro para as medidas de proteção química e bactereológicas sistemáticas e preventivas que, por mutação genética, conduzem a uma seleção de cepas de bactérias ou parasitas resistentes aos antibióticos e aos pesticidas, enquanto, paralelamente, os alvos potenciais, humanos, florísticos ou faunísticos podem ser fragilizados.

O princípio de precaução só pode então ser aplicado sobre os maiores riscos técnico-cientificos coletivos, como os que são induzidos, por exemplo, pelos OGM, pelas doenças como a encefalopatia espongiforme bovina, pelas tecnologias de transporte ou pela produção de energia, como o Corcorde ou a energia nuclear, mas nunca sobre mercados camponeses! A definição do interesse geral é, no momento, um assunto delicado, pois caberá ao juiz avaliar a importância do risco coletivo que justifica o recurso a esse princípio, particularmente em matéria de proteção da natureza e da conservação da biodiversidade. Se for tomado, por exemplo, o caso dos contenciosos nacionais e comunitários ligados à caça, perceber-se-á que a aplicação rigorosa do princípio de precaução, fundado nas dificuldades de conservação de certas populações de pássaros migradores, ${ }^{14}$ pode levar a um questionamento das tradições cinegéticas regionais, às quais as populações rurais são profundamente ligadas. A preservação da biodiversidade justifica o recurso sistemático ao princípio de precaução, que encontra evidentemente uma justificativa na queda de certos estoques haliêuticos no Atlântico Norte ou no desmatamento massivo das zonas tropicais? A proteção

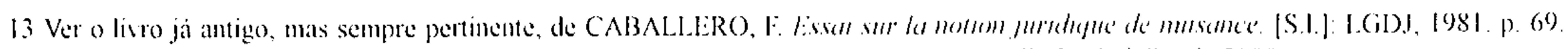

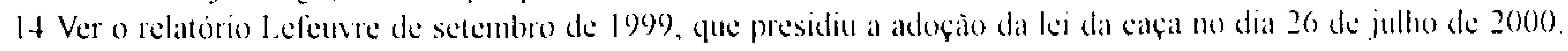


de um inseto ou uma planta, de acordo com a diretiva fauna/flora/habitat $92 / 43$, pode impedir a realização de uma obra de incontestável utilidade pública? Ainda aqui, seria talvez útil proceder à criação jurisprudencial e doutrinal, referindo-se, por exemplo, aos princípios de gestão biológica adotados pela União Internacional para a Conservação da natureza, como o do uso dos recursos naturais renováveis, mencionado recentemente no novo artigo L420 do Código Ambiental. Tais princípios, fundados sobre a idéia de um equilíbrio entre a legitimidade da ação humana sobre a natureza e o respeito da integridade dos ecossistemas, poderiam ajudar o juiz em seu arbítrio.
Em quaisquer das hipóteses, as instâncias jurisprudenciais nacionais e européias, cada vez mais acionadas pelos contra-poderes associativos, deveriam ser levadas a precisar o alcance e os limites do princípio de precaução. Competindo com as instâncias legislativas, elas serão então inevitavelmente obrigadas a proceder politicamente, como começaram a fazer em outros domínios. Dessa última observação, resulta que em um assunto desse gênero o papel do direito tem seus limites, fazendo com que a implantação do princípio de precaução seja inevitavelmente conflituoso. 